\title{
Six Key Influences on the Efficiency of Insourcing in State and Local Plans
}

\author{
Michael A. Urban
}

Michael A. Urban is a research associate in finance and geography at the University of Oxford's School of Geography and the Environment in Oxford, U.K.

michael.urban@ouce.ox.ac.uk

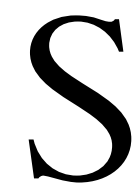
ince 2001, U.S. state and local pension plans have been facing severe underfunding. By 2008, Novy-Marx and Rauh [2009] estimated that underfunding was close to US $\$ 3.23$ trillion. Although the financial markets' upturn supported a partial recovery, a nationwide pension crisis is still looming. At stake is the potential failure of these institutions, which could further precipitate the failure of state and local governments. In 2016, state and local plans represented the interests of 25 million members, including 14.7 million active participants and 10.3 million beneficiaries who were distributed US $\$ 282.9$ billion in retirement benefits (Vidal [2017]). ${ }^{1}$ Notwithstanding the cost to taxpayers, the direct social and economic consequences of the failure of these institutions would be devastating. Aside from the numerous local particularities in underfunding (Munnell et al. [2014]) and process (see Clark and Monk [2014] on investment management agreements), commentators have noted commonalities deemed instrumental in improving the health of these institutions. In particular, Munnell et al. [2015] have stressed the importance of adequate contributions and investment returns.

As argued by Clark and Monk [2017], however, plans "can be held hostage to local

${ }^{1}$ This amount does not include withdrawals and other payments. interests." For example, during recessions, the fall in tax revenues has impelled state and local governments to significantly reduce their contributions in an effort to balance their use of public resources (Munnell et al. [2015]). Commentators have also noted that recent years' difficult fiscal conditions have pushed governments to resort to privatization to reduce the costs of public administration (Keefe [2012]). As noted by Clark and Monk [2013], the investment functions of public pension plans have traditionally largely been outsourced to private sector asset managers and consultants.

A growing number of studies, however, show that institutional investors such as pension funds and sovereign wealth funds (SWFs) can significantly reduce costs and improve net investment performance by insourcing their investment functions. CEM Benchmarking found that pension funds' median cost of internal management is materially lower than that of external management, a finding that is consistent across asset classes for active strategies (MacIntosh and Scheibelhut [2012]). In a global study on pension plans, Clark and Urwin [2008] estimated that external management costs are 10 times greater than internal management costs. Finally, a study sponsored by the Maryland Public Policy Institute has shown that state plans paying the highest Wall Street fees were 
also consistently underperforming their peers (Hooke and Walters [2013]).

Although the available evidence points to the clear benefits of insourcing, its implementation has not been a straightforward process. A small number of beneficiary institutions have embraced the model with success, but the majority has remained largely outsourced. This finding is apparent in several studies. Dixon and Monk's [2014] global study of institutional investors shows evidence that, despite grassroots movements of insourcing among public pension systems and SWFs, assets keep flowing toward private sector contractors largely based in and around international financial centers (IFCs), which highlights the enduring centralization and agglomeration of investment service provision. Another empirical study specifically dedicated to state and local plans showed that during the 2006-2012 period, the majority of public pension assets were consistently outsourced to private contractors (Urban [2018c]).

The prevalence of outsourcing in the United States contrasts sharply with Canadian pension plans, which have long been recognized by scholars, experts, and the media as the champions of insourcing (e.g., see Bachher and Monk [2012]; The Economist, [2012]). Commonly referred to as the Canadian model, the approach has entailed both an extensive use of internal resources to keep control over investment costs and aggressive investment strategies with significant allocations toward alternative investments (The Boston Consulting Group [2015]). The results of Canadian plans are noteworthy, but the replicability of their model across different political and economic contexts is uncertain.

In the United States in particular, pension experts have emphasized that the gap between public pension investment managers' compensation compared with international peers and national private sector financial institutions represents a major impediment to insourcing (Ambachtsheer et al. [2008]; Clark and Monk [2013]). However, compensation is only one part of an intricate puzzle. For instance, recent research suggests that differences in plans' local environment in relation to access to specialized labor markets and external contractors impacts public plans' insourcing strategies (Urban [2018a]). Whereas financial institutions traditionally thrive in close spatial proximity, the devolvement of the management of state and local governments' pension assets to local government institutions means that each state and local pension plan is embedded in a specific local political, economic, and regulatory environment.

With close to 4,000 individual public pension plans accounted for by the U.S. census, "the local dominates the global" (Clark and Monk [2014]). As a consequence, insourcing has to be considered in light of the possibilities to implement global investment functions from varied local environments. Acknowledging this fundamental characteristic, this article aims to discuss insourcing by public pension plans along six key influences. In that sense, this is not a best-practice article proposing a blueprint for insourcing. Instead, it proposes a set of analytical building blocks to evaluate its implementation across varied local environments.

These six key influences are drawn from a larger research project on insourcing and outsourcing among state and local plans. They are based on an empirical analysis relying on mixed methods combining qualitative and quantitative data. The data were collected over the past 4 years. These included the analysis of public records - public retirement systems' websites, data collected by nonprofit organizations - and more than 50 interviews with public pension executives, investment staff, private sector investment managers, consultants, and pension experts. Original quantitative data on state pension plans' insourcing strategies were also collected and analyzed in two separate research projects (Urban [2018c]; Urban [2018a]); these supplement and cross-validate the qualitative insights.

The article is organized as follows. The first section reviews insourcing as an important yet underappreciated solution in addressing a looming retirement crisis. The argument is presented bearing in mind the large differences in the functionalism and organizational arrangements of state and local pension plans. The second section sets the stage for the core of the article. In particular, it considers state and local plans' heavy political underpinnings, lax regulatory environment, and varied governance structures and discusses their implications for insourcing. The third and main section unpacks the six key influences on the efficiency of insourcing: cash flows, economies of scale, asset allocation, compensation, location, and fiduciary duty and oversight. They are discussed individually as well as in relation to one another, and their significance is illustrated with case studies and secondary quantitative data analysis. 


\section{THE LOCAL DOMINATES THE GLOBAL}

State and local pension plans are organized to fulfill a mission of public interest. Specifically, they are charged through delegated authority to collect, manage and distribute retirement assets for government employees. Despite the uniformity of their mission, organizational arrangements vary considerably among plans. Investment and administrative functions are at times separated and at times integrated. Board of trustees' composition, plans' choice to insource or outsource their investment functions, and their use of intensive or extensive delegation also all vary considerably across institutions. Functionalist critiques hold that such organizational diversity is inconsistent with the imperatives that come with managing financial assets under risk and uncertainty. Clark [2008] argues that this difficulty may be mitigated by expertise on the part of plans' decision-makers. However, even though the model trumps organizational quirks, it remains fragile and vulnerable to changes among board members and key investment staff.

Although I contend that large structural reforms according to a strict functionalist blueprint are unrealistic and undesirable, I argue in favor of a hybrid investment strategy that combines in- and outsourcing in a way that is tailored to different organizational arrangements and contexts. Given the considerable diversity in the public pension landscape, there is a real need to approach the field with ontological flexibility. The diversity in shapes and sizes of state and local retirement systems in the United States is a direct product of the devolved authority flowing from federal to local governments. Here the "local dominates the global," so that particular local political and economic contexts largely dictate state and local plans' organizational arrangements. This contrasts with private pension systems, which are subject to federal regulations (Clark and Monk [2014]).

The state legislator typically has overall authority over pension regulation but delegates the investment of contributions and the administration of benefits through a set governance structure. Once again, governance structures vary considerably between plans. Although state legislators should theoretically only have a role of oversight, they can micromanage unhelpfully in a number of ways. One way is through the introduction of legislative bills. These can include a wide array of provisions that have disruptive effects on the management of pension assets (both investment and administration). Examples include altering a plan's benefits structure (see the recent example of Illinois unsuccessfully attempting to alter its pension promises; Supreme Court of Illinois [2015]), placing limits on asset allocations (see Mitchell et al. [2000]; Clark and Monk [2013a]), or introducing a targeted investment ban (see the Florida Statutes, which prohibit investments in institutions doing business in or with Cuba). Miller and Funston [2014] also underline problematic involvement in the approval of operating budgets, staff headcount, and plans' staff compensation policies.

\section{GOVERNANCE AND INSOURCING}

Statutes delimit the structure, responsibilities, and composition of plans' board of trustees. To help navigate structural differences, Miller and Funston [2014] provide a useful classification of governance structures based on close examination of the fifty-five largest state plans. The most widely adopted model has one fiduciary board that delegates both the investment and the administration of the assets to a single organization. The second most represented model has a fiduciary board that has a sole investment focus, while the administration of benefits is devolved to a separate organization. The third model has one fiduciary board that delegates investment functions to one entity and the administration of benefits to another. The least common model has a sole fiduciary (not a board of fiduciaries), typically the state comptroller or treasurer, who delegates pension investments to her/his department investment staff through a CIO. There is a separate benefits administration organization with its own board that reports to another entity (not the sole fiduciary).

Boards of trustees' size and composition vary significantly across plans (Andonov et al. [2016]). These variations have been extensively researched in relation to pension plans' investment and funding performance. Ambachtsheer [2007] suggests that substantive differences in governance are associated with differences in the range of 100 to 300 basis points (bps) in investment returns per year. For instance, Yang and Mitchell [2005] studied the effect of board composition on funding status. They found that the presence on boards of active and/or retired plan participants reduces funding ratios, thus suggesting that the representation of members' interest on the board may conflict with investment imperatives. Munnell et al. [2008] found 
mixed results on the relation between funding ratios and board composition but also found that plans with a separate investment council had, on average, funding ratios $4.9 \%$ higher than those without. Dobra and Lubich [2013], who also obtained inconclusive results on board composition, found that board size affects asset allocation, with larger boards taking larger risk exposure. Finally, looking specifically at private equity investments, Andonov et al. [2016] found that the presence of ex officio and participant elected board members negatively impacted plans' investment returns in the asset class. Their research pointed to conflicts of interest affecting fund performance in instances where ex officio board members received political contributions from the financial industry.

These results stress the fundamental importance of the presence of investment expertise on a board. Ultimately, good governance should be founded upon expert pension management and sheltered from political interferences. Clark [2004] noted that generally, the model of governance observed in pension funds as well as the "knowledge and competence" of pension funds" trustees are not adapted to the complexity of contemporary financial markets. While it would seem desirable and effective to have both expertise and authority flowing topdown from the board to the investment functions, there are a number of instances where expertise is represented effectively at lower levels through set delegation structures.

This is the case in a fiduciary management model in which the design of the investment strategy is delegated to an external agent. Here authority and responsibility over the plan's investments are transferred to an external provider (Clark and Urwin [2017]). In this model, board level expertise is only incidental in its ability to select and negotiate a competent and competitive provider. Fiduciary management has the merit of limiting boardled strategic and tactical misallocations that occur in instances when boards are charged with designing the investment strategy and yet lack the expertise to do so. A board's lack of investment expertise is, however, very problematic in the hub-and-spokes model, where an investment strategy designed by the board is then implemented by a number of external contractors. Serious mistakes in asset allocation made by boards that lack investment expertise and/or have hidden agendas are likely to incur significant losses in investment performance (Brinson et al. [1986]), regardless of the execution of external contractors.
Based on these considerations, the article argues that insourcing can not only be a cost-efficient investment model, but also has the merit of fostering essential skills and expertise inside the organization. Under this model, boards of trustees, sometimes in conjunction with an investment subcommittee, design the overall investment strategy, which is then implemented using internal staff capabilities. That said, in practice, there are no entirely in-sourced public pension plans, and this strategy is usually pursued in conjunction with the help of external consultants, for third-party oversight and guidance, and external managers, to fill the gaps in internal expertise. These insourced or rather hybrid plans nonetheless have substantial technological infrastructure and human capital that allow them to implement a significant portion of their investment strategy in a timely and direct fashion and monitor their entire portfolio using internal resources. Here, expertise is represented at different levels of authority within the organization. Top-down investment decisions emanating from the board are filtered through several layers of internal expertise, including the CIO, asset class heads, investment managers, analysts, traders, and risk managers. This hierarchy insures that investment decisions are assessed, negotiated, and implemented dynamically inside the organization (see Urban [2018b] for a detailed description of a large hybrid pension plan).

As discussed, good governance correlates positively with fund performance. Good governance does not necessarily depend on a specific structural design but rather is anchored in mechanisms that allow decision-makers to efficiently and effectively manage stakeholders' expectations. Ambachtsheer et al. [2008] note: "Instead of providing oversight to the pension organization, Boards, and to a lesser degree, management, can get involved in sorting out the respective financial interests of retirees, active workers, future workers and sometimes even those of bond holders, shareholders or current and future taxpayers." To address these conflicting expectations, Clark and Urwin [2008] proposed a set of governance best practices. They identified three dimensions by which the quality of practice can be gauged-namely, mission, people, and process. In a nutshell, these three dimensions prescribe the following: 1) a clearly formulated and stated organizational mission supported by adequate resources; 2) a strong investment expertise among investment decision makers; and 3) a fundwide investment process. 
The effectiveness of their proposition stems from its versatility. Rather than propose a fixed model of pension governance that might dictate board of trustees' size, structure, and responsibilities, the authors address its moving parts to insure adaptability across a large range of structures. The six key influences on the efficiency of insourcing proposed hereafter were identified in that same spirit - an attempt to conciliate practical relevance with flexibility. Although each influence is further discussed in reference to specific research, a number of key scholarly works on institutional investors and public pension plans underpin them.

The first two influences, cash flows and economies of scale, are largely inspired by Clark and Monk's latest book Institutional Investors in Global Markets [2017] and prior journal articles (Clark and Monk [2013b, c], [2016]). Influence three, asset allocation, is identified as needing separate discussion in part because of its recognized importance in financial economics (Brinson et al. [1986]), but more specifically because of the importance it plays for insourcing in relation to human capital requirements to manage diverse global balanced institutional portfolios (for empirical demonstration and discussion, see Urban [2018a, b]). Influence four, compensation, is deemed important because of the fundamental role it plays in the competition for talent between financial institutions (Philippon and Reshef [2012]) and the persisting difficulties of public plans in attracting and retaining talented investment professionals (Clark and Urwin [2008]; Clark and Monk [2013b]). Influence five, location, is grounded in the work conducted by Dixon and Monk [2014] on frontier finance and the implications of location on the insourcing strategies of institutional investors that find themselves at a distance from financial agglomerations. Finally, influence six, fiduciary duty and oversight, is anchored in Clark and Urwin's [2017] comparative discussion on fiduciary management, hub and spokes, and insourcing.

\section{SIX KEY INFLUENCES ON THE EFFICIENCY OF INSOURCING}

\section{Influence 1: Cash Flows}

Insourcing requires substantial investments and organizational changes. In order for the associated costs to be fully amortized over time, plans need to be in a position to reasonably expect continuity of operations.
In general, plans facing adverse cash flows would be ill advised to invest in internal capabilities. Cash flows are influenced in a number of ways-notably, by demographic change. A mature plan with a growing ratio of retirees per contributors will face negative cash flows.

Legislative decisions can also affect plans' cash flows. The most obvious is the decision to freeze and/or close a defined-benefit (DB) system and replace it with a defined-contribution (DC) system. These initiatives seldom happen overnight and usually reflect a commitment on the part of legislators to different systems of retirement (DB versus DC). Systems embedded in a political environment that has an established record of pushing for the institution of DC systems may be well advised to avoid engaging in costly organizational changes. Broader public administration decisions, such as budgetary cuts and privatization, affecting the size of the state and local government workforce, and as a result the number of plan participants, will also affect future cash flows.

Cuts in sponsor contributions, widespread in times of budgetary deficit, also need to be considered. Compared to public plans in other countries, public pension plans in the United States offer considerable room for maneuvering to reflect the wishes of local constituencies when it comes to funding. U.S. public plans have no funding ratio requirement, unlike with other jurisdictions, which typically set a funding floor for retirement systems. Dutch pension plans, for instance, are required to be funded at $105 \%$. The Governmental Accounting Standards Board (GASB), which defines state and local government accounting standards, defines the actuarially required contribution (ARC) as the dollar amount of contributions plans should pay in to cover their projected liabilities.

No mechanism exists to enforce this rule, however, so public administrations have the latitude to undercontribute and defer responsibility. This flexibility allows local governments to make trade-offs over competing uses of public resources, be it to manage budgetary deficits or peruse political strategies. Unfortunately, undercontributions can significantly affect funding ratios and place pension plans in precarious positions (Munnell et al. [2015]). Exhibit 1 shows the marked increase in ARC as a percentage of payroll and the concomitant rise in unpaid contributions since 2001. Between 2001 and 2016, while the aggregate ARC increased from 5\% to $16.5 \%$ of payroll, unpaid contributions increased from $0 \%$ to $5 \%$, peaking at $18.7 \%$ in 2011 . 


\section{E X H I B I T 1}

ARC and Unpaid Contributions (2006-2016)

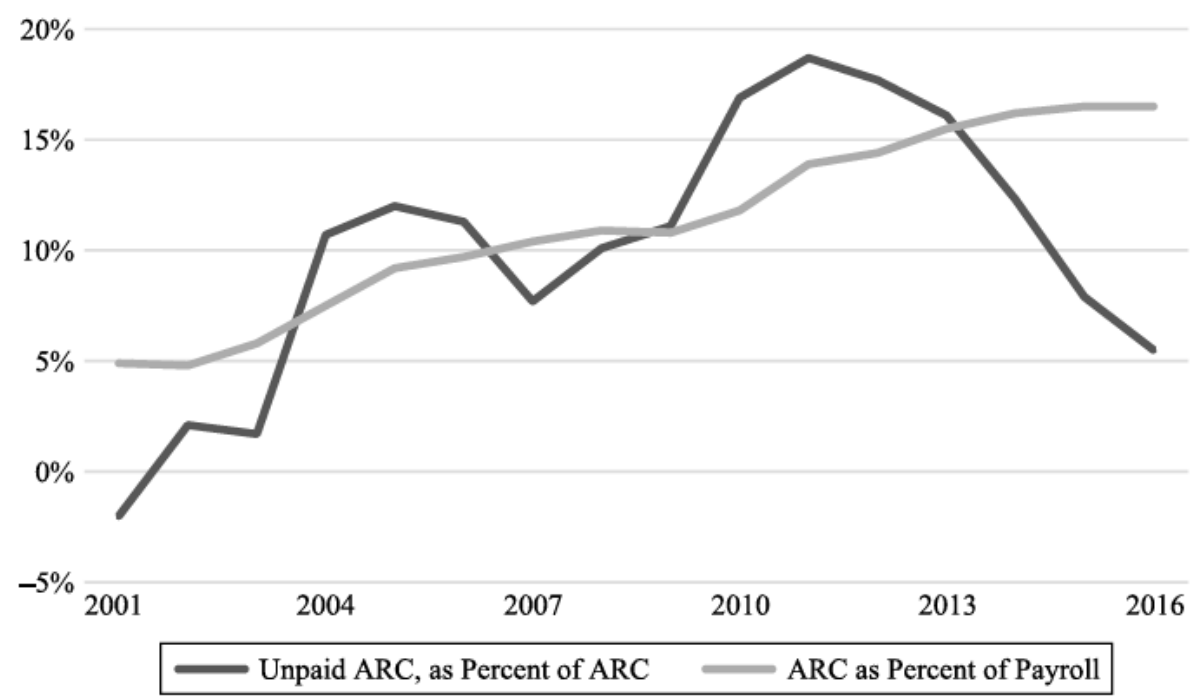

Source: Authors' calculations, based on national data from the Center for Retirement Research at Boston College (CRR) [2016].

Brown and Wilcox [2009] argue that current accounting standards allow state and local pension plans to disguise the sheer size of their unfunded liabilities. The behavior is incentivized by current regulation allowing public pension plans to use expected investment returns as a discount rate for projected liabilities. A study by Andonov et al. [2015] has expanded on this issue by demonstrating how plans' investment risk increases as plans artificially improve their funding status through inflated investment return objectives. Current lax regulatory standards may conceivably cause a vicious circle that particularly affects plans in precarious situation: A plan with a lower funding ratio faces a higher ARC that is unlikely to be met, especially when the sponsoring government faces significant budgetary deficits; in an effort to mask the effect of undercontributions, plans increase investment return objectives and change their portfolio allocation with the hope that investment returns will make up for unpaid ARC. This simply increases the fund's risk-return profile. In adverse market conditions, funding ratios are negatively impacted twice through skimpy contributions and investment losses; in turn, this has the effect of incentivizing further relative cuts in contributions, matched by further pressure to increase market return expectations.

Overall, supportive cash flows that demonstrate a political commitment to public sector services and DB retirement systems are essential for successful insourcing. No matter how sound the investment strategy, inadequate contributions will always risk inadequate funding and cannot be realistically compensated by financial market returns. While building internal capabilities offers substantial benefits, it should not be pursued as a cost management strategy to make up for a fundamentally weak financial position.

\section{Influence 2: Economies of Scale}

Industry experts and scholars alike contend that the size of assets under management (AUM) largely determine funds' ability to perform internal management. Clark [2004] states: "Few pension funds are large enough in terms of their assets to provide both the routine and the highly specialized tasks and functions at competitive performance-related prices." Dixon and Monk [2014] also assert that, in their experience, US $\$ 25$ billion is the threshold under which institutional investors such as pension plans and SWFs have not been able to internalize asset management in a meaningful way. Although there are clear economies of scale in asset management (see Collins [2003] for a detailed empirical discussion), the view ought to be taken with a pinch of salt.

Based on data collected by the Maryland Public Policy Institute on the management fees paid in 2014 
by 31 state plans ranging from US $\$ 2$ billion to US $\$ 300$ billion, Exhibit 2 shows that the relationship between assets size and total fees spent by public pension plans is not as clear as suggested. For instance, a number of "small" institutions managed to keep external fees low. Overall, fees ranged from $0.101 \%$ to $0.758 \%$ of AUM; these minimum and maximum ratios were paid by a US $\$ 42$ billion and US $\$ 81$ billion plan, respectively. Average fees paid out were $0.413 \%$. The sample's standard deviation was $0.178 \%$. The absence of a clear linear relationship ( $\mathrm{R}$-squared $=0.0798$ ) suggests that factors other than total scale dictate the costs of asset management. If anything, the relationship between asset size and the costs of outsourcing would be expected to be negative, with larger plans paying lower management fees (expressed as a percentage of total AUM). Generally, I would argue that total scale does not matter as much as the manner in which the plan operationalizes its investment functions. The use of internal management, passive strategies, or avoiding expensive asset classes all offer investment solutions to keep costs down regardless of size. This will later be discussed in more detail in relation to asset allocation.

The same can be said about the relationship between scale and the proportion of assets that plans manage in-house. Whereas all pension plans share the same mission to fund future liabilities, their strategic responses in terms of in- versus outsourcing have been shown to vary according to several criteria, many of which take precedent over economies of scale. Recent econometric research has shown that the proportion of assets managed internally by state pension plans is expected to grow by only $0.1 \%$ for every $1 \%$ increase in plan size (approximated using total membership). On the other hand, the study revealed the importance of other factors pertaining to asset allocation decisions (discussed in Influence 3) and the location of plans (discussed in Influence 5). It also predicted that for every $1 \%$ increase in the assumed rate of return (ARR), an additional $12.1 \%$ of total assets is allocated to external contractors (Urban [2018a]).

In light of the way that DB pension plans design their investment strategies, these findings are not particularly surprising. DB pension funds' primary objective is to meet their projected liabilities, which is assumed to be achieved through a combination of the annual employer contribution (ARC) and ARR, the targets for both of which are established through actuarial methods. As discussed previously, because there are no legal requirements for plans to meet their ARC, actuarial targets are often tweaked in practice. As a result, investment return objectives can be inflated to make up for undercontribution by state sponsors (Brown and Wilcox [2009]; Munnell et al. [2015]).

\section{E X H I B I T 2}

Total AUM (US\$ billion) vs. Total Investment Management Fees as Percentage of AUM (2014)

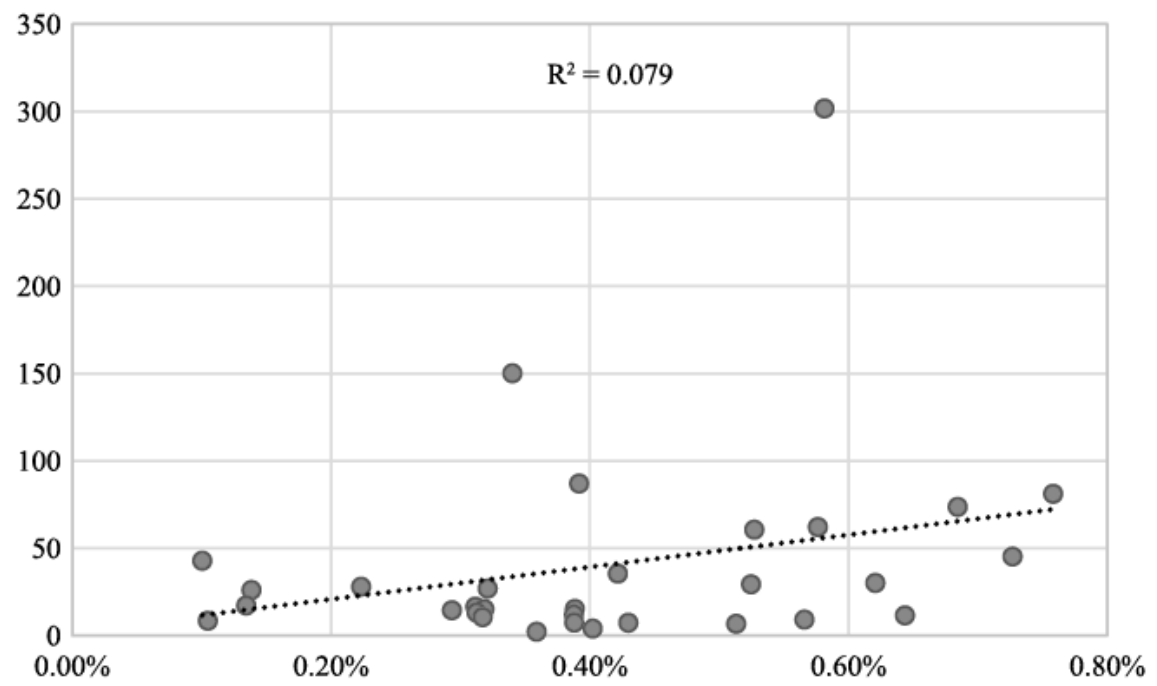

Source: Author's calculation, based on data from the Maryland Public Policy Institute. 
Once a target investment return is established, portfolio theory can be applied to determine an optimal strategic asset allocation that minimizes a fund's total risk for the given return objective. An asset class specific target return and risk budget are then established. These are then weighted against market return expectations to choose between an active or a passive strategy. If the targets exceed expected market returns, the need for alpha (returns in excess of a given market benchmark) will call for an active strategy. This process is schematically represented in Exhibit 3. Overall, rather than a fund's total scale, it is the scale and performance objectives of individual asset classes that will determine the choice to either insource or outsource.

\section{Influence 3: Asset Allocation}

Whereas total AUM may not provide the best starting point to think about in-versus outsourcing, asset allocation and investment strategies help address the dilemma in a more granular way. Indeed, the management of different types of assets calls for different needs in human and technological capital. In general, as the complexity of investments increases, investment management tends to become more human capital

\section{E X H I B I T 3}

\section{Scheme of Investment Process in DB Public Plans}

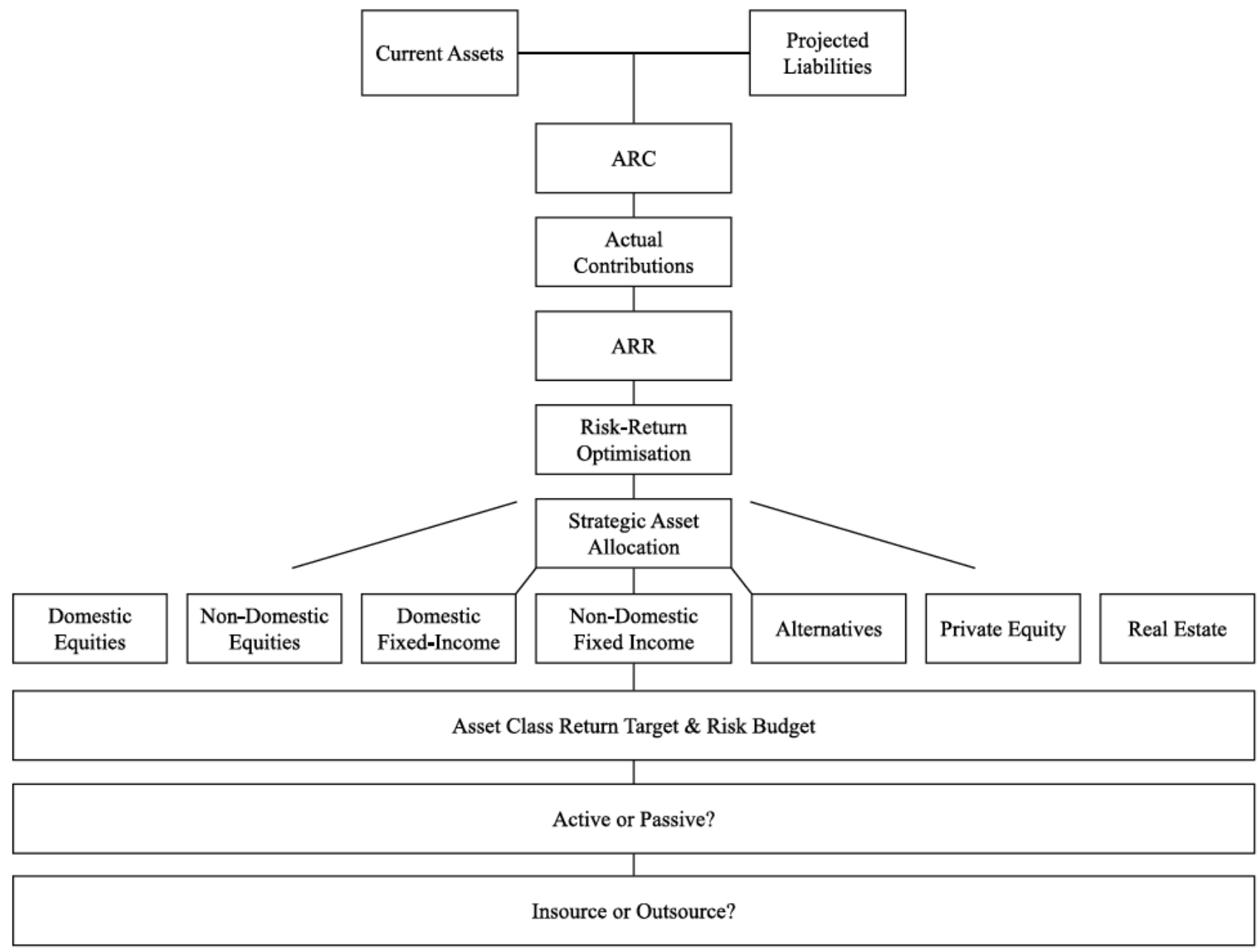

Source: Author. 
intensive and require larger technological infrastructure. Conversely, less complex investments tend to be less human capital intensive and require smaller technological infrastructure. Here, the degree of complexity is to be understood as related to the liquidity and efficiency of assets, the degree of sophistication in the way they are traded, and the way they are assembled into a comprehensive investment strategy. A U.S. large-cap equity portfolio is a typical example of a low-complexity investment strategy that assembles long exposures to highly efficient and liquid assets. A hedge fund, on the other hand, is a typical example of a complex investment strategy. It may assemble long and short trades seeking to minimize market exposure (market neutral strategy) and may invest in inefficient and illiquid assets (distressed or relative value strategies).

In public pension plans with limited budgetary resources, internal management should be geared toward liquid and efficient investments, particularly public markets in equities and investment-grade debt. Generally, internal active strategies may be better suited to larger plans, given the fact that these strategies require more resources than passive ones. Interestingly, a growing number of players have decided to abandon active management. The most notable example is the Public Employees' Retirement System of Nevada, which ascribes to a passive and outsourced model of investment management. As of 2016, 91\% of the plan's assets of US $\$ 36$ billion were invested in public markets covering U.S. and non-U.S. equities and fixed income. The fund employs a single investment manager that oversees a highly concentrated selection of external managers. Since 2015, its assets have been invested entirely through externally managed index funds distributed among six managers. Another four managers cover the plan's securities lending and private market commitments. Finally, the fund uses the services of only two external consultants. In 2016, it paid US $\$ 18$ million in total annual fees (Martin [2016]), which corresponds to only 5 bps (compared to the $41 \mathrm{bp}$ average external management fees, calculated and shown in Exhibit 2). Overall, the fund stands out as one of the best-performing plans in the country. Replicating this low-complexity model using internal resources could yield further cost savings.

However, a fund's appetite for superior investment returns will inevitably push plans toward more complex, less scalable, and less flexible asset classes that require scarce investment expertise. In particular, investment in alternative asset classes effectively requires both a large pool of illiquid capital and internal know-how (Boston Consulting Group [2015]). In general, investment expenses (internal and/or external) increase as complexity increases. These expenses primarily reflect the pay premium for human capital encompassing scarce investment management skills and expertise, as is typical in asset classes such as hedge funds and private equity. Regardless of total AUM, these asset classes are unlikely to be managed internally by pension plans because the required skills and expertise are prohibitive, especially for plans subject to legislative budgetary approval. The only option is then to either outsource or avoid these asset classes entirely. This choice, of course, needs to be weighed with the risk-return objectives of the fund. When considering the former solution, there are clear advantages of having sizable commitments to complex asset classes in negotiating fees with external providers.

A study by CEM Benchmarking covering 1998-2011 notes that public pension plans with less than US $\$ 2$ billion in AUM underperformed their larger peers. This was in part due to small plans' underperformance in U.S. small-cap equities, real estate, and private equity, which trailed their peer group by 115 , 109, and 407 bps, respectively. While the study does not get into further details, the author notes that underperformance is "at least in part, due to higher investment costs relative to the other fund type/size cohorts" (Beath [2014]).

This relationship is further demonstrated in Exhibit 4, which illustrates a stronger linear relationship between plans' allocations to alternatives and total investment costs $(\mathrm{R}$-squared $=0.375)$. By comparing Exhibit 4 with observations from Exhibit 2, it may be argued that total investment costs are more a function of allocation to alternatives than of total AUM. For small plans, the investments costs associated with complex asset classes may outweigh the return benefits. While small plans may prefer to stay away entirely, there are reasons that may entice sizable plans to do the same thing. With more than US $\$ 300$ billion, CalPERS decided to divest its US $\$ 4$ billion hedge fund commitment in 2014 over cost and complexity concerns (Marois [2014]).

To be sure, fund size should not determine whether plans should or should not do internal management; instead, it should determine how to do it. Overall, and regardless of size, plans should focus their internal 


\section{E X H I B I T 4}

Allocation to Alternatives as Percentage of AUM and Total Investment Management Fees as Percentage of AUM (2014)

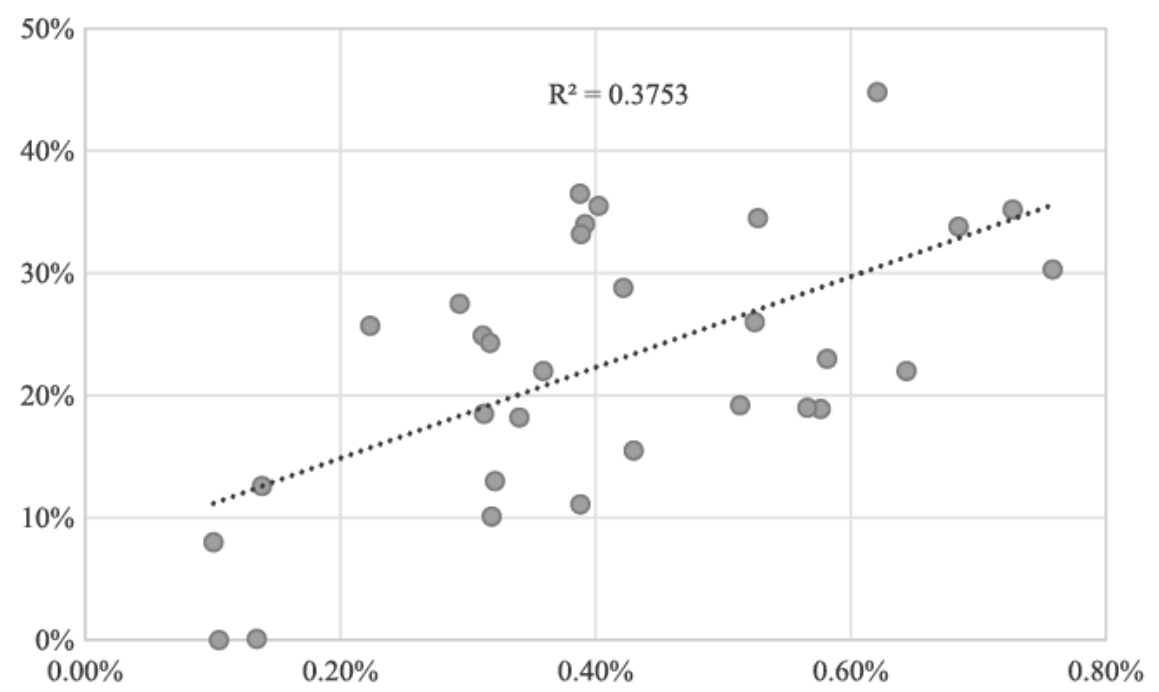

Source: Author's calculation, based on data from the Maryland Public Policy Institute.

capabilities in investments where they can add value in a cost-effective way, within the limits imposed by the legislature on their operational budget.

\section{Influence 4: Compensation and Source of Current Expenditure Financing}

Canadian pension funds have gathered a lot of attention over the past 10 years. Coined as the Canadian model and pioneered by Ontario teachers in the 1990s, a number of Canadian plans successfully brought a majority of their assets in-house. But their superior investment returns are not just the result of their larger internal capabilities. According to a recent report by the Boston Consulting Group [2015], Canadian plans owe their investment success to a combination of low-cost internal management as well as to their distinctive asset allocation. Their sizable commitment toward alternative investments, which average $32 \%$, was rewarded by superior returns in private equity in particular. In comparison, their U.S. peers allocate only $16.4 \%$ of their assets to alternatives.

Although the Canadian model has demonstrated its merits, it cannot likely be replicated in any meaningful way in the United States for at least two reasons, both rooted in the heavy legislative interference imposed on
U.S. plans. First, the legislation of a number of states imposes potentially restrictive allocation ceilings by asset class. Second, U.S. public plans continue to offer some of the least competitive compensation packages, making it difficult for plans to attract and retain talented investment professionals across asset classes, particularly managers of complex classes. A global study of large pension institutions (MacIntosh and Scheibelhut [2012] showed marked cross-country compensation differences. Canadian funds pay the highest compensation to their investment staff, with annual salaries averaging US $\$ 536,000$; followed by Europe, US $\$ 246,000$; the United States, US $\$ 148,000$; and Australia and New Zealand, US $\$ 139,000$. Salary differences of similar magnitude are observed for governance, operations, and support functions.

These differences result, in most cases, from the fact that expenses on internal capabilities are billed to the legislative branch. This contrasts with external management fees, which are charged directly to plan assets. For instance, the Oregon State Treasury, which manages over US $\$ 72$ billion in DB assets, recently made a second attempt to convince the state legislature to add US $\$ 10$ million to its operating budget to recruit an extra 30 investment professionals and extend its current inhouse capabilities (P\&I Online [2017]). US $\$ 10$ million is a sum large enough for a public administration to 
want to consider the demand carefully. Relative to the plan's asset base, however, the extra budget represents only 1.39 bps, a small commitment in comparison to the average 41.3 bps paid by state plans on external management fees in 2014.

From a legislator's point of view, satisfying public opinion may at times take priority over plan efficiency. Because of the differences in accounting treatments between internal and external management costs, every penny spent on internal resources is subject to public scrutiny, whereas fees paid for external management services go relatively unnoticed. Given the lack of popularity of public pension plans, often perceived as a minority privilege collectively sponsored by tax payers, elected officials tend to worry over the political costs of allocating public resources toward public pension systems. As a consequence, public plans' operating budgets tend to be slim, effectively forcing them to turn to the market for investment services. Over the long run, this tendency is highly counterproductive, given the large savings that could be achieved through in-house asset management.

The current system is also perverse, given that taxpayers ultimately bear responsibility for public pension liabilities. The current double standard in the treatment of internal and external investment expenses distorts the perception of the problem. In a nutshell, it discourages unnecessary legislative spending, increases future costs, and generally disguises negative consequences. In the future, public plans that keep overpaying for external management fees are more likely to have to tap into taxpayers' money to pay benefits. One solution would be to give public pension plans the autonomy to manage their operating budgets independently and charge funds' assets directly. Internal and external expenses would then both affect the funds' net performance, and the structure of internal and external management would be optimized according to a strict economic logic. Another solution would be to make external management costs part of a fund's operating budget. Under this system, both internal and external management costs would be subject to public scrutiny. This would require the public and elected representatives to address the question of whether public resources should be spent on Wall Street fees or local public servants.

While the political dynamics underpinning investment staff compensation differentials among state and local plans continue to pose significant challenges, it has been argued that some public plans have been able to adopt creative recruitment strategies to hire at the margin of labor markets (Dixon and Monk [2014]). Rather than try to compete directly with private sector financial institutions, resource-constrained pension plans and SWFs have been shown to recruit strategically. One solution has been to observe a countercyclical recruitment strategy, hiring private sector talents at a discount during slack skilled labor markets. In particular, the sustained labor market contraction that followed the 2008-2009 financial crisis has provided fertile ground for public plans. A more long-term strategy followed by public plans has been to offer qualitatively superior working conditions compared to private sector firms in order to compensate the quantitative discount in pay.

In a detailed case study and analysis of skilled labor in public pension plans, Urban [2018b] showed the advantages of recruitment differentiation tactics focused around improved work-life balance and a collaborative work environment. This stands in contrast with private sector norms that tend to value intensity of effort and personal concessions and nurture a silo mentality that rewards individual, not collective, performance. Since most pension plans are located in small to midsize metropolitan areas, lower costs of living were also shown to help justify lower base pay compared to the high wages and high cost of living observed in and around large financial centers. Finally, in order to keep employees incentivized to think and act comprehensively to achieve a total fund return objective, incentive compensation has been kept below industry levels and structured to put a premium on total fund return as opposed to rewarding asset class or individual performance.

\section{Influence 5: Location}

Plan location in relation to private sector providers of financial products and services also plays a significant role in dictating in-versus outsourcing strategies. A study of 21 state plans over the period from 2006-2012 indicates that plans embedded in a vibrant local financial sector as well as those in proximity of leading IFCs (New York, Boston, Chicago, and San Francisco) are significantly more likely to outsource their investment management (Urban [2018a]). Plans co-located with a vibrant financial sector may have greater difficulty attracting investment professionals since the pay gap becomes more apparent. Co-located plans face the difficulty of having to offer 
lower compensation packages relative to the industry, without the benefit of either an enhanced quality of life (e.g., congestion, pollution, commuting times) or a lower cost of living. Close physical proximity with a financial agglomeration also likely nurtures a relational proximity with the industry that may discourage public plans from trying to replicate the functions of top-tier financial institutions.

As discussed, total AUM as an isolated concept is a weak predictor of public plans' insourcing strategies. It may, however, play a significant role in the outsourcing of investment functions when considered in relation to plans' relative proximity to hubs of private sector contractors. In general, scale gives room for choice. A large co-located plan such as CalPERS (US\$300+ billion), based in Sacramento only a few miles from San Francisco, is in a strong position to negotiate fees and cultivate close relationships with external contractors. On the other hand, a large isolated plan such as the State Board Administration of Florida (SBA; US $\$ 150+$ billion), based in Tallahassee, represents enough business potential for external contractors to be willing to undergo four-hour flights via Atlanta. When it comes to outsourcing, scale transcends geographical distance.

Considering insourcing, on the other hand, the SBA may be at a slight advantage compared to CalPERS, given the fact that it does not have to compete with a vibrant local financial sector. Initially, given the small local labor pool, it may be harder to recruit experienced talent nationally in highly competitive markets. For prospective employees, the relocation process may be a disincentive to join the SBA. On the other hand, isolation may help retention given the absence of local professional alternatives. Lower local cost of living in Tallahassee compared to Sacramento also helps justify lower compensation. Base salary for an investment manager position at CalPERS is set at US $\$ 175,000$, compared to US $\$ 127,000$ at the SBA. Differences become more significant when including variable compensation, which is substantial at CalPERS (about $40 \%$ of base pay) and capped below market standards at the SBA. The gap that is not explained by lower cost of living is likely due to differences in political support and public acceptance of government employees' compensation policies in California and Florida-historically progressive and conservative states, respectively.

Small plans have less flexibility when considering relationships with external providers, which has a bearing on the impact of location. In general, small players are expected to be at a disadvantage because their business potential is too small to negotiate preferential fees. For the same reason, they are also less likely to receive the degree of personal care external contractors would dedicate to larger plans. When plans are isolated (located afar from contractors), the problem is likely to increase. As the relationship grows more distant, so does the quality of oversight, which may result in poor interest alignment. Being small and distant is probably the weakest position to be in when considering external management.

This challenge may be, at least in part, overcome through the buildup of internal management capabilities. Given the strong relationship between costs and complexity, small plans choosing insourcing should try to focus their internal, if not all, their resources on long, passive, and low-turnover strategies. However, because small plans tend to have lower funding ratios than their larger peers, they are also more likely to have an increased appetite for more complex and active strategies. This is problematic, given the evidence that small plans are generally unsuccessful at managing complex strategies because of higher management costs (Boston Consulting Group [2015]). These recommendations are summarized in Exhibit 5.

\section{Influence 6: Fiduciary Duty and Oversight}

Working in the best interests of their clients, board members ought to deploy an investment strategy that is consistent with the fund's net risk-adjusted investment return objectives. The main impediment to the fulfilment of this objective is political interference that "right-skews" investment objectives. This is likely to happen when public plans become entangled with larger public administration considerations and legislators transfer part of their responsibility for contributions

\section{E X H I B I T 5 Location vs. AUM}

\begin{tabular}{|l|c|c|c|}
\cline { 3 - 4 } \multicolumn{2}{c|}{} & \multicolumn{2}{c|}{ Total AUM } \\
\cline { 3 - 4 } \multicolumn{2}{c|}{} & Small & Large \\
\hline $\begin{array}{l}\text { Location Relative } \\
\text { to Financial } \\
\text { Agglomerations }\end{array}$ & Connected & Outsource-mix & Choice-mix \\
\cline { 2 - 4 } & Isolated & Insource & Choice-mix \\
\hline
\end{tabular}

Source: Author. 
onto the board's responsibility for investment returns. In turn, this problem will lead to suboptimal deployment of the fund's assets, reflected in a fund's asset allocation and its implementation (insourcing, outsourcing), and ultimately, it will lead to inferior investment returns.

As argued previously, the current regulatory vacuum incentivizes a problematic chain of decisions in public pension plans. In particular, the fact that shortcomings in ARC can be artificially offset by inflated ARR ultimately leads plans to shoot for unrealistic returns. Fundamentally, net risk-adjusted investment return objectives and corresponding investment strategies (asset allocation and insourcing) should not be driven artificially by the funding needs of the plan (as determined by actuarial projections) but chosen based on financial market prospects and costs of implementation. This fine and complex balance requires shrewd investment expertise. Different combinations of funding status, legislative commitment to adequate contribution levels, and financial market prospects will call for different asset allocation strategies leading to different target returns and implementation. For the resulting strategy to be effective it will not only have to perform well on a risk-adjusted gross return basis but also be cost effective. In general, fiduciary duty and investment management expertise should dictate pension plans' investment strategies and trump conflicting stakeholders' agendas.

Arguably, effective cost management may provide the basic rationale for fostering internal capabilities. Having internal skills and expertise as well as technological infrastructure can also play a critical role in guaranteeing a board's ability to exercise its responsibility of oversight in a timely way. In instances where pension plans comprehensively adopt fiduciary management, the problem is, at least in theory, resolved, as investment responsibilities are delegated to an external agent. Clark and Urwin [2017] state: "Fiduciary management is understood as the outsourcing of the framing and implementation of investment strategy when using a number of external managers to fulfil a total fund objective, conforming to investment mandates and redundancy between mandates." However, as the authors note, fiduciary management still requires good governance to function effectively.

Regardless of the mode of investment management-hub and spokes, fiduciary management, or insourcing - a combination of high-level internal expertise and access to timely and transparent information is critical to support good governance and efficient investment outcomes. Across all three models, board-level investment expertise should be a priority and constitutes a nonnegotiable building block of plans' internal capabilities. To guarantee proper oversight, further internal capabilities may be required, depending on differences in investment strategy and implementation. For the purpose of this discussion, these are stylized into three key strategies.

Under Model A, plans adopt an almost entirely passive and low-complexity investment strategy. In this case, because index trackers entail no proprietary information in terms of allocation, holdings can be reconciled and accessed in real time with basic technological means. Under this model, transparency of information is almost guaranteed. Given the low complexity as well as the passive nature of the strategy (index tracking and low intervention), it also requires very little human capital. This model can be adopted by co-located and distant plans alike. It is also accessible to small, medium, and large plans with the differing governance structures typically observed in state and local plans, as long as fiduciaries can attest to minimum investment management expertise. This model is likely to be embraced by plans that have superior funding ratios and can afford to aim for investment returns that reflect global market returns on balanced strategies.

Under Model B, plans adopt a mixed strategy of actively and passively managed accounts. Because active strategies entail proprietary information, investment managers can be wary of seeing their processes and models appropriated and replicated by competitors and clients. To protect their integrity, external active managers may not guarantee continuous access to their holdings. This will leave gaps in oversight when external managers can take opportunistic bets that fall outside of their mandate. As a result, the diversification strategy of the plan may be temporarily compromised. Furthermore, investments across mandates delegated to different external managers might overlap. ${ }^{2}$

Under this model, building internal capabilities that combine asset class-specific expertise, together with a technological infrastructure that guarantees daily access through a single custodian account, can be a costeffective way to guarantee timely oversight. The model requires acceptance and support from the legislature, as it

\footnotetext{
${ }^{2}$ Typically, a U.S. mid-cap manager may take an opportunistic position in a small-cap fund to improve the return of its fund. The client might end up with undesired overlapping investments between its mid- and small-cap managers.
} 
requires more significant budgetary commitments than Model A. Internal investment capabilities will be biased toward long-term investments in efficient and liquid asset classes, while expertise gaps in more-complex asset classes will be filled by external mandates. This model is highly scalable and should be within the reach of plans of different sizes. Because recruitment is an important component of the model, location in conjunction with compensation policies are central to its effectiveness.

Under Model C, plans adopt a predominantly active strategy. This strategy is the most capital-intensive model and corresponds to the Canadian model. It requires internal resources that are most likely beyond the reach of U.S. public pension plans given their current budgetary constraints, regardless of size. The issues regarding their governance are, however, the same as the ones encountered under Model B. The recruitment of a small team capable of selecting capable specific asset managers and providing effective oversight would be advisable. As with Model B, those plans would also be advised to invest in the minimum technological infrastructure allowing timely and comprehensive access to their fund's holdings through a single custodian.

\section{CONCLUSIONS}

This article has built on the evidence suggesting that insourcing could be an important part of the solutions aimed at improving the health of state and local pension plans. Recognizing the significant differences that exist across a varied landscape regrouping close to 4,000 individual public plans, it emphasizes that insourcing needs to be strategically implemented in reference to particular contexts and circumstances and, ideally, be supported by a larger set of reforms.

Particularly, one would hope that the GASB would enforce new standards for discounting liabilities in calculating public plans' funding ratios. Ideally, these standards would be the same as those currently enforced for private sector pension plans, which require discount rates to be calculated as a function of current interest rates (Crossley and Jametti [2013]). This would have the effect of clarifying the political discussion on the future of these institutions with a fairer representation of their true budgetary costs. It would also be desirable to institute new regulations that force state and local governments to meet their required contributions. These measures would eliminate the current practice of transferring sponsors' responsibility for contributions onto boards' responsibility for investment returns.

Last but not least, one would hope to see significant cohesive changes in the governance structure of state and local plans. Particularly, and as noted by previous commentators, a board of trustees must have adequate investment expertise (Clark and Urwin [2008]). This is foundational in insulating the investment operations of public pension plans from political interference. It is the author's sincere hope that he may witness the materialization of such a leap in political courage. This combination of regulatory and governance reforms would provide a healthy base to implement fundwide investment programs that use insourcing and outsourcing in the most efficient way, given contextual particularities.

Caught between idealism and skepticism, realism forces us to consider and address the current dynamics that shape state and local pension plans. This position is taken in this article and underlines the proposed influences on the efficiency of insourcing. Whereas a future change of paradigm is desirable, the proposed perspectives have the merit of offering instrumental flexibility across a varied landscape of institutions without the need for major legislative reforms. Overall, the correct appreciation of the role of the six influences offers a comprehensive framework to strategically consider insourcing as an investment model that can be highly cost effective and improve fundwide oversight. Finally, whereas this article primarily follows and addresses recent debates on the benefits of insourcing and outsourcing for institutional investors, it also points to an interesting third alley to improve net returns by focusing on minimizing investment costs. The "do-nothing" approach (Martin [2016]), which focuses on low-turnover passive strategies in public markets and is powerfully exemplified by the Public Employees' Retirement System of Nevada, should be followed closely and may provide inspiration to fix complex problems with simple solutions.

\section{ACKNOWLEDGMENTS}

This research was supported by the Smith School of Enterprise and the Environment, University of Oxford, and by the European Research Council (ERC) under the European Union's Horizon 2020 research and innovation programme (grant agreement number 681337). The article reflects only the authors' views, 
and neither the Smith School nor the ERC is responsible for any use that may be made of the information it contains. The author thanks Gordon Clark, Rajiv Sharma, Adam Dixon, Sandy Mackenzie, and Philip Urban for providing precious comments on previous drafts of this article. None of the above should be held responsible for the opinions expressed herein.

\section{REFERENCES}

Ambachtsheer, K. Pension Revolution: A Solution to the Pensions Crisis. New York: John Wiley, 2007.

Ambachtsheer, K., R. Capelle, and H. Lum. "The Pension Governance Deficit: Still With Us.” Rotman International Journal of Pension Management, Vol. 1, No. 1 (2008), pp. $14-21$.

Andonov, A., R. Bauer, and K. Cremers. "Pension Fund Asset Allocation and Liability Discount Rates: Camouflage and Reckless Risk Taking by US Public Plans?” 2015, http:// papers.ssrn.com/sol3/papers.cfm?abstract_id=2070054.

Andonov, A., Y.V. Hochberg, and J.D. Rauh. "Political Representation and Governance: Evidence from the Investment Decisions of Public Pension Funds." 2016, https://ssrn.com/ abstract $=2754820$.

Bachher, J.S., and A.H.B. Monk. "Attracting Talent to the Frontiers of Finance." The Sovereign Wealth Fund Initiative, Summer 2012.

Beath, A.D. "Asset Allocation and Fund Performance of Defined Benefit Pension Funds in the United-States between 1991 and 2011." 2014, https://www.reit.com/sites/ default/files/pdf/Asset\%20Allocation $\% 20$ and $\% 20$ Fund $\% 20$ Performance\%20Merged\%20With\%20Title\%20Page\%20 (12May2014).pdf.

Boston Consulting Group. "Measuring Impact of Canadian Pension Funds." 2015, https://www.optrust.com/documents/Measuring\%20Impact $\% 20$ of $\% 20$ Canadian $\% 20$ Pension $\% 20$ Funds.pdf.

Brinson, G.P., L.R. Hood, and G.L. Beebower. "Determinants of Portfolio Performance." Financial Analysts Journal, Vol. 42, No. 4 (1986), pp. 39-44.

Brown, J.R., and D. Wilcox. "Discounting State and Local Pension Liabilities." American Economic Review: Papers and Proceedings, Vol. 99, No. 2 (2009), pp. 538-542.
Center for Retirement Research at Boston College (CRR). "Public Pension Plans National Data." 2016, http://publicplansdata.org/quick-facts/national/.

Clark, G.L., "Pension Fund Governance: Expertise and Organizational Form." Journal of Pension Economics and Finance, Vol. 3, No. 2 (2004), pp. 233-253.

Clark, G.L., and A.H.B. Monk. "Financial Institutions, Information, and Investing-at-a-Distance." Environment and Planning A, Vol. 45, No. 6 (2013a), pp. 1318-1336.

- - "Principles and Policies for In-House Asset Management." The Journal of Financial Perspectives, Vol. 1, No. 3 (2013b), pp. 1-9.

- - "The Scope of Financial Institutions: In-sourcing, Outsourcing and Off-shoring." Journal of Economic Geography, Vol. 13, No. 2 (2013c), pp. 279-298.

- " "State and Local Pension Fund Governance and the Process of Contracting for Investment Services: The Scope of Diversity and the Problem of Embeddedness." Territory, Politics, Governance, Vol. 2, No. 2 (2014), pp. 150-172.

——. "Ambiguity, Contract, and Innovation in Financial Institutions." Competition \& Change, Vol. 20, No. 3 (2016), pp. 187-203.

Institutional Investors in Global Markets. Oxford: Oxford University, 2017.

Clark, G.L., and, R. Urwin. "Best-Practice Pension Fund Governance." Journal of Asset Management, Vol. 9, No. 1 (2008), pp. 2-21.

" "The Outsourced Chief Investment Officer Model of Management and the Principal-Agent Problem." The Journal of Retirement, Vol. 4, No. 3 (2017), pp. 28-41.

Collins, S. “The Expenses of Defined Benefit Pension Plans and Mutual Funds." Perspectives, Vol. 9, No. 6 (2003), pp. 1-19.

Crossley, T., and M. Jametti. "Pension Benefit Insurance and Pension Plan Portfolio Choice." The Review of Economics and Statistics, Vol. 95, No. 1 (2013), pp. 337-341.

Dixon, A.D., and A.H.B. Monk. "Frontier Finance." Annals of the Association of American Geographers, Vol. 104, No. 4 (2014), pp. 852-868. 
Dobra, M., and B.H. Lubich. "Public Pension Governance and Asset Allocation." JCC: The Business and Economics Journal, Vol. 6, No. 1 (2013), pp. 83-101.

The Economist. "Maple Revolutionaries." 2012, http://www .economist.com/node/21548970.

Hooke, J., and J.J. Walters. "Wall Street Fees, Investment Returns, Maryland and 49 Other State Pension Funds." The Maryland Public Policy Institute, 2013.

Keefe, J. "Public Employee Compensation and the Efficacy of Privatization Alternatives in US State and Local Governments." British Journal of Industrial Relations, Vol. 50, No. 4 (2012), pp. 782-809.

MacIntosh, J., and T. Scheibelhut. "How Large Pension Funds Organize Themselves: Findings from a Unique 19-Fund Survey." Rotman International Journal of Pension Management, Vol. 5, No. 1 (2012), pp. 34-40.

Martin, T.W. “What Does Nevada’s \$35 Billion Fund Manager Do All Day? Nothing.” Wall Street Journal, 2016, https:// www.wsj.com/articles/what-does-nevadas-35-billion-fundmanager-do-all-day-nothing-1476887420.

Miller, B.R., and R. Funston. "Public Pension Governance That Works." 2014, https://www.nasra.org/Files/ Topical\%20Reports/Governance\%20and\%20Legislation/ FunstonGovernance1403.pdf.

Mitchell, S.O., D. McCarthy, S.C. Wisniewski, and P. Zorn. "Developments in State and Local Pension Plans." In Pensions for the Public Sector. Edited by O.S. Mitchell and E. Hustead. Philadelphia: University of Pennsylvania Press, 2000.

Munnell, A.H., J. Aubry, and M. Cafarelli. "How Did State/ Local Plans Become Underfunded?" State and Local Pension Plans, No. 42 (2015), pp. 1-7.

Munnell, A.H., K. Haverstick, and J.P. Aubry. "Why Does Funding Status Vary Among State and Local Plans?" State and Local Pension Plans, No. 6 (2008), pp. 1-12.

Munnell, A.H., J.P. Aubry, J. Hurwitz, and M. Medenica. "The Funding of State and Local Pensions: 2013-2017." State and Local Pension Plans, No. 39 (2014), pp. 1-14.
Novy-Marx, R., and J.D. Rauh. "The Liabilities and Risks of State-Sponsored Pension Plans." Journal of Economic Perspectives, Vol. 23, No. 4 (2009), pp. 191-210.

Marois, M.B. "Calpers to Exit Hedge Funds, Divest $\$ 4$ Billion Stake." Bloomberg, 2014, https://www.bloomberg .com/news/articles/2014-09-15/calpers-to-exit-hedgefunds-citing-expenses-complexity.

P\&I Online. "Oregon State Funds Seek to Beef Up Staff." 2017, http://www.institutionalinvestor.com/Article .aspx?ArticleId=3719656\&utm_medium=email\&utm_cam paign $=$ Essential+II+Daily $+5242017 \&$ utm_content $=$ Essen tial+II+Daily+5242017+CID_1d59f0dab38ddbbe8beb0cc 91e5abf49\&utm_source=CampaignMonitorEmail\&utm_ term $=$ Oregon + State + .

Philippon, T., and A. Reshef. "Wages and Human Capital in the U.S. Finance Industry: 1909-2006." The Quarterly Journal of Economics, Vol. 127, No. 4 (2012), pp. 1551-1609.

Supreme Court of Illinois. "In re Pension Reform Litigation (Doris Heaton et al., Appellees, v. Pat Quinn, Governor, State of Illinois, et al., Appellants)," 2015.

Urban, M.A. "Autarky in State and Local Pension Plans: A Test of the Make-or-Buy Thesis." Under review, Economic Geography, 2018a.

- - "Producing Investment Returns at the Margin of Finance: A Frontier Talent Proposition." Geoforum, forthcoming, 2018b.

___. "Public Pension Finance: Are State and Local Plans Running away from Wall Street?" Under review, Territory, Politics and Governance, 2018c.

Vidal, P.M. "Annual Survey of Public Pensions: State-and Locally-Administered Defined Benefit Data Summary Brief: 2016." July 2017, https://www.census.gov/content/dam/ Census/library/publications/2017/econ/g16-aspp-sl.pdf.

Yang, T.S., and O.S. Mitchell. "Public Pension Governance, Funding, and Performance: A Longitudinal Appraisal." 2005, https://www.pensions-institute.org/workingpapers/ WP2005-2.pdf.

To order reprints of this article, please contact David Rowe at drowe@iijournals.com or 212-224-3045. 